\title{
FAKTOR-FAKTOR YANG MEMPENGARUHI PEMBELIAN PRODUK GARAM DAN AIR MINERAL BERMEREK DI JAKARTA
}

\author{
Randy Ramadhiansa \\ Program Studi Magister Manajemen Universitas Tarumanagara \\ randryvrr@gmail.com
}

\begin{abstract}
The addition of salt products and branded mineral water in Jakarta, a way to increase the purchase of a product is needed. he study was conducted with the aim of understanding the brand awareness of consumers and analyzing the attitude of consumers towards selected branded commodity food products. An attempt was made to examine the items influencing the purchase of selected branded commodity food products. The product chosen in this research is salt and mineral water branded in Jakarta. Sample taken from 200 respondents residing in Jakarta area of various age, gender, last education, and work. Results show visible packaging, people around, bazaars, people around, and advertising is the most important source of awareness of branded salts. availability of nutritional information, references from friends and relatives, easy availability, and price as the most important factor in purchasing branded salt and branded water. free from adulterants, free from insecticides / pesticides / harmful chemicals and social status as the most important parameters of branded salt and branded mineral water.There is a significant perception difference regarding the importance of the various factors and parameters that influence the purchase of branded and branded branded mineral water amongst respondents by demographics. This paper offers insights and information for salt and mineral water producers in Jakarta in order to address the key factors that affect consumer purchases.
\end{abstract}

Keywords : Branded Product, Commodity food products, Brand awareness, Jakarta, Consumer behaviour, Brands, Demographics.

\section{PENDAHULUAN}

Pada zaman yang modern ini kebutuhan manusia semakin beragam. Hal tersebut tercermin pada tingkat kebutuhan masyarakat yang semakin beragam dan semakin meningkat. Mulai dari peningkatan kebutuhan primer ataupun sekunder. Namun dari sekian banyak kebutuhan manusia, kebutuhan pangan, sandang, dan papan masih menjadi kebutuhan pokok yang selalu menempati urutan teratas dalam hal permintaan. Menurut Kementrian Industri dan Perdagangan, kebutuhan bahan pokok terbagi menjadi Sembilan yaitu beras, gula pasir, sayur-sayuran, daging sapi, ayam, minyak goring, susu, telur, garam, dan minyak tanah. Paling pertama dan yang sehari-hari masyarakat konsumsi adalah garam dan air mineral.

Konsumen sekarang mulai lebih memilih asupan makanan berkualitas dan menjadi lebih sadar dalam hal diet gizi, masalah kesehatan dan keamanan pangan (Rimal, 2001). Sebagai hasil dari meningkatnya kebutuhan dan keterjangkauan, sebuah persepsi baru bahwa "dikemas secara higienis dan bermutu tinggi" menghasilkan penjualan makanan bermerek dan yang berkembang pesat. Persepsi tersebut akan diuji validitasnya pada dua bahan kebutuhan pokok, yaitu garam dan air mineral.

Garam adalah salah satu kebutuhan terpenting dalam kehidupan sehari-hari. Kebutuhan garam nasional tahun 2014 mencapai 3,85 juta ton, terdiri dari garam konsumsi sebesar 1,73 juta ton dan garam industri 2,13 juta ton. Hal ini mengingat hampir seluruh masyarakat Indonesia mengkonsumsi garam sebagai bahan masak wajib pakai. Dengan ini, garam mempunyai peluang yang besar untuk dikembangkan, terutama di bagian perdagangan. 
Banyaknya garam bermerek yang beredar sebagai konsekuensinya, para konsumen jadi harus lebih teliti untuk memilih garam bermerek mana yang memiliki kualitas lebih bagus.

Kebutuhan air semakin lama semakin meningkat sejalan dengan meningkatnya kebutuhan hidup manusia, baik di daerah perkotaan maupun daerah perdesaan. Menurut Asosiasi Perusahaan Air Minum dalam kemasan Indonesia (2016) Kebutuhan air dalam kemasan terus mningkat dari tahun ketahun. Kebutuhan air minum kemasan Indonesia mencapai 23,1 miliar liter pada tahun 2014 dan tahun 2016 konsumsi meningkat 11\% menjadi 26,5 miliar liter. Perusahaan air mineral memproduksi air mineral dalam bermerek agar air bersih tersebut dapat dikonsumsi secara praktis dan mudah oleh masyarakat dengan harga yang terjangkau, hal ini dikarenakan perusahaan memproduksi air mineral tersebut dengan berbagai macam bermerek ukuran yang dapat disesuaikan dengan kebutuhan konsumen. Menurut Richard Will (2003) seiring berkembangnya air mineral bermerek menjadi barang konsumsi yang sulit dipisahkan dalam keseharian masyarakat.

Dalam persaingan merek produk, citra merek (brand image) air minum ataupun garam dalam bermerek merupakan hal yang penting bagi suatu produk untuk tetap bertahan dalam persaingan antar produk. Kesadaran merek (brand awareness) merupakan hal yang penting bagi konsumen untuk menentukan keputusan pembelian. Menurut (Kotler dan Armstrong, 2010) mengemukakan bahwa konsumen dapat melewatkan beberapa tahap selama pembelian rutin.Semakin ketatnya persaingan antar merek air mineral dan garam bermerek, konsumen dituntut untuk lebih selektif dalam memilih dan menentukan merek yang akan dibeli. Konsumen dituntut mempelajari dan mengefaluasi merek untuk dijadikan pedoman dalam menentukan keputusan pembelian. Kesadaran merek konsumen berperan penting di dalam tercipta kepuasan pada suatu merek, hal tersebut juga berpengaruh terhadap keputusan pembelian kembali konsumen dimana jika konsumen puas dengan suatu merek produk tertentu maka konsumen memiliki kecenderungan untuk melakukan pembelian ulang. Menurut (Scheidel, 2001) definisi demografi adalah Demografi, studi tentang ukuran, struktur dan perkembangan populasi manusia. Menurut penelitan dari Dirard (2010) dan Akbar (2010) faktor-faktor dari demografi ini sangat berpengaruh positif terhadap atribut suatu produk dan berpengaruh secara signifikan juga terhadap pembelian. Maka itu, dengan adanya garam dan air mineral bermerek ditambah dengan adanya perbedaan tingkat ekonomi di masyarakat dalam penelitian ini peneliti ingin mengetahui brand awareness dan sikap dari konsumen terhadap garam dan air mineral bermerek ini.

Penelitian ini diharapkan dapat memahami brand awarness pada konsumen dan mengetahui sikap konsumen terhadap produk garam dan air mineral bermerek yang dipilih. Selain itu juga dilakukan untuk menguji faktor dan atribut mana yang mempengaruhi pembelian produk garam dan air mineral bermerek yang terpilih.

\section{LANDASAN TEORI \\ Brand Awareness}

Menurut (O'Guinn, Allen dan Semenik, 2009) brand awareness merupakan indikator penting mengenai pengetahuan konsumen tentang suatu merek produk, kekuatan dari kehadiran suatu merek di benak konsumen dan betapa mudahnya pengetahuan dapat diambil dari memori konsumen. Menurut (MacDonald dan Sharp, 2000) dalam membuat suatu keputusan konsumen dapat menggunakan brand awareness. Contohnya, Saat mereka mengenal nama produk mereka, produk tersebut akan menjadi salah satu list pertimbangan pembelian konsumen tersebut. Selain itu brand awareness juga dapat membantu konsumen untuk lebih memahami kategori produk atau layanan yang diberikan suatu perusahaan/suatu produk dagang mereka.

\section{Attitude of Consumers.}

Menurut Louis (2006) mendefinisikan sikap adalah - "jumlah total kecenderungan dan perasaan manusia, prasangka, atau bias, gagasan, ketakutan, ancaman, dan keyakinan yang 
telah terbentuk sebelumnya tentang topik tertentu". Attitude of Consumers itu sendiri memiliki definisi perasaan favorableness atau ketidakmampuan terhadap penawaran produk atau layanan. Dalam konteks Attitude of Consumers, perasaan konsumen akan mencerminkan sesuatu yang dapat menguntungkan ataupun tidak menguntungkan secara konsisten, dalam hal objek yang ditawarkan. Contoh objek : harga, toko, dealer, penjual, iklan, promosi, dan penjualan.

\section{Purchased Intention}

Menurut (Schiffman dan Kanuk, 2007) Purchase Intention adalah sesuatu hal yang mewakili konsumen yang mempunyai kemungkinan, akan, rencana atau bersedia untuk membeli suatu produk atau layanan di masa depan. Suatu produk dapat dikatakan dikonsumsi bila konsumen telah memutuskan untuk membeli produk tersebut. Minat pembelian dipengaruhi oleh value suatu produk. Konsumen membeli suatu produk biasanya didasari oleh rangsangan stimuli dari luar diri dia sendiri. Rangsangan itu kemudian diproses sebelum akhirnya memutuskan untuk membeli produk tersebut. Selain dari rangsangan luar, minat juga dipengaruhi oleh faktor dari dalam diri konsumen itu sendiri.

\section{BAHAN DAN METODE}

Penelitian ini menggunakan teknik pengambilan sampel judmental sampling. Responden dihubungi di rumah mereka dan datanya dikumpulkan dengan wawancara pribadi dengan responden yang dipilih dengan bantuan kuesioner terstruktur. Responden yang diambil ditentukan dari umur 18 keatas, dengan latar belakang pendidikan dan pekerjaan yang berbeda-beda. Data yang terkumpul dianalisis dengan menggunakan berbagai alat statistik seperti mean score, standar deviasi, dan analisis varians. pertanyaan yang berisi penilaian berbagai faktor seperti harga, citra merek, ketersediaan mudah, tampilan menarik, rekomendasi pengecer, referensi dari teman / saudara, kemasan, ketersediaan informasi nutrisi, informasi tentang tanggal kadaluarsa, responden diminta untuk menilai atribut / Faktor-faktor di atas skala Likert lima poin ("5" berarti "yang paling penting" dan "1" berarti "paling tidak penting"). Penelitan juga diuji dengan uji validitas dan reabilitas untuk setiap pertanyaannya.

\section{HASIL DAN PEMBAHASAN}

Pengumpulan data dilakukan dengan mengggunakan kuisioner yang disebarkan kepada 200 responden. Menurut usia responden terbagi menjadi 83 responden untuk 18-25 tahun, 99 responden 26-40 tahun, dan 18 responden diatas 40 tahun. Jenis kelaminnya responden terbagi menjadi 56 responden untuk laki-laki dan 144 untuk perempuan. Profesi responden didominasi oleh karyawan sebesar 95 responden, 68 siswa/I, 20 responden wirausaha, dan 17 responden ibu rumah tangga. Pendidikan terakhir responden didominasi oleh perguruan tinggi sebesar 91 responden, SMA 86 responden, SD 12 responden, dan SMP 11 responden. Responden didominasi mengeluarkan diatas Rp. 3.000 .000 per bulan sebanyak 86 responden, 45 responden sebesar Rp. 1.000.000,00 - Rp. 1.999.999,00, 38 responden sebesar Rp. 2000.000,00 - Rp. 3.000.000,00, 22 responden Rp. 700.000,00 - Rp. 999.999,00, dan 7 responden mengeluarkan dibawah Rp. 700.000,00.

Responden ditnyakan mengeani pengetahuan tentang garam dan air mineral bermerek. Ditemukan pada 200 responden $100 \%$ dapat menyebutkan tiga merek air mineral bermerek, dengan merek yang bermacam-macam, "Aqua", "Ades", "Nestle", "Prime", "Vit", "Le Minerale", "Evian", dan "2tang". Garam bermerek terdapat 45 responden (22,5\%) yang hanya dapat menyebutkan satu garam bermerek, 66 responden (33\%) hanya dapat menyebutkan dua garam bermerek, dan ada 89 responden $(44,5 \%)$ dapat menyebutkan tiga garam bermerek. Merek garam bermerek yang disebutkan para responden antara lain”Dolpin”,"Dolina", "Refina", Trisalin", Cap Kepiting”, "Segitiga Emas", Cap Neayan”, Ikan Layang", "Octopus", Cap jempol”, "Krista”, "Burung Laut", "Cap Daun”, dan "Cap 
Kapal”. Kesadaran merek dapat mempengaruhi persepsi, sikap, dan dapat bertindak sebagai penggerak pilihan produk bermerek dan bahkan kesetiaan terhadap suatu produk.

Responden disuruh memilih faktor mana yang paling penting dalam memperkenalkan garam dan air mineral bermerek. Responden mengganggap kemasan yang terlihat adalah sumber paling penting terhadap kesadaran garam bermerek.

Orang sekitar masuk juga dianggap penting bagi responden, kemudian bazaar. Sedangkan untuk air mineral bermerek, responden menganggap kemasan yang terlihat masih menjadi sumber paling penting, orang sekitar, dan iklan sebagai faktor penting. Seperti yang dikatakan bahwa iklan cenderung memengaruhi keakraban konsumen dengan produk makanan baru, karena semakin sering orang melihat merek yang diiklankan, semakin dikenal. Upaya periklanan harus diarahkan untuk meningkatkan tingkat kesadaran konsumen muda (Markovina et al., 2011).

Menurut (Sondoh, 2007) harga, kualitas produk, packaging, dan brand sebagai parameter yang menjadi pertimbangan dalam pembelian dari suatu produk, rasa biasanya datang di atas preferensi konsumen saat produk makanan dipertanyakan. Para responden diminta untuk menilai berbagai parameter garam bermerek dan air mineral bermerek dengan skala likert. Responden menganggap bebas dari campuran bahan berbahaya, bebas dari pestisida dan bahan kimia berbahaya, status sosial, kualitas produk bersertifikat, rasa /rasa yang lebih baik, gizi, ketersediaan mudah sebagai atribut penting dari garam bermerek. Dalam pernyataan ini, responden melaporkan bahwa pengemasan yang mudah dibawa, lebih mudah didapatkan, dan memiliki rasa yang lebih baik sebagai parameter yang disetujui responden mempengaruhi pembelian air mineral bermerek. (Tabel. 1)

Tabel 1. Hasil Persepsi Responden Terhadap Beberapa Parameter Garam dan Air Mineral Bermerek

\begin{tabular}{|c|c|c|c|c|c|c|c|c|c|}
\hline & $\begin{array}{c}\text { Garam bermerek } \\
\text { lebih Bergizi dari } \\
\text { pada garam } \\
\text { tanpa merek }\end{array}$ & $\begin{array}{c}\text { Garam bermerek } \\
\text { memiliki rasa lebih } \\
\text { baik dari pada } \\
\text { garam tanpa }\end{array}$ & $\begin{array}{l}\text { Garam bermerek bebas } \\
\text { dari campuran bahan } \\
\text { berbahaya dari pada } \\
\text { garam tanpa merek }\end{array}$ & $\begin{array}{c}\text { Garam bermerek } \\
\text { adalah suatu produk } \\
\text { bersertifikasi } \\
\text { berkualitias }\end{array}$ & $\begin{array}{c}\text { Garam bermerek } \\
\text { dapat } \\
\text { meningkatkan } \\
\text { status sosial }\end{array}$ & $\begin{array}{c}\text { Garam } \\
\text { bermerek } \\
\text { terlalu } \\
\text { mahal }\end{array}$ & $\begin{array}{c}\text { Garam } \\
\text { bermerek bebas } \\
\text { dari insektisida / } \\
\text { bahan kimia }\end{array}$ & $\begin{array}{c}\text { Garam bermerek } \\
\text { mudah di } \\
\text { dapatkan di } \\
\text { sekitar rumah }\end{array}$ & $\begin{array}{c}\text { Garam bermerek } \\
\text { memiliki } \\
\text { pengmasan } \\
\text { mudah dibawa }\end{array}$ \\
\hline \multicolumn{10}{|l|}{ Garam } \\
\hline Mean & 3,30 & 3,64 & 3,51 & 3,91 & 2,58 & 3,04 & 3,36 & 3,79 & 3,97 \\
\hline SD & 1,295 & 1,17 & 1,288 & 1,064 & 1,331 & 1,279 & 1,338 & 1,046 & 1,102 \\
\hline Responden & 200 & 200 & 200 & 200 & 200 & 200 & 200 & 200 & 200 \\
\hline \multicolumn{10}{|l|}{ Air Mineral } \\
\hline Mean & 3,59 & 3,94 & 3,60 & 3,97 & 2,68 & 3,35 & 3,41 & 4,58 & 4,26 \\
\hline SD & 1,415 & 1,212 & 1,296 & 1,091 & 1,469 & 1,247 & 1,422 & 0,636 & 0,902 \\
\hline Responden & 200 & 200 & 200 & 200 & 200 & 200 & 200 & 200 & 200 \\
\hline
\end{tabular}

Hasil perbandingan tanggapan konsumen pada parameter yang mempengaruhi peningkatan pembelian garam bermerek sehubungan dengan demografik (usia, jenis kelamin, pendidikan, dan penghasilan) menunjukan bahwa ada perbedaan signifikan dalam tanggapan mengenai "garam bermerek lebih bergizi dari pada garam bermerek", "Memiliki rasa yang lebih baik", "campuran bahan berbahaya". Sedangkan hasil perbandingan tanggapan konsumen pada parameter yang mempengaruhi peningkatan pembelian air mineral bermerek sehubungan dengan demografik (usia, jenis kelamin, pendidikan, dan penghasilan) menunjukan bahwa ada perbedaan signifikan dalam tanggapan mengenai "air mineral bermerek lebih bergizi dari pada garam bermerek", "Memiliki rasa yang lebih baik", "bebas dari campuran bahan berbahaya", "bersertifikasi berkualitas", "dapat meningkatkan status sosial", "terlalu mahal", bebas dari insektisida / bahan kimia", dan "mudah didapatkan". Jadi terbukti hipotesis pertama jika terdapat perbedaan persepsi yang signifikan mengenai pentingnya berbagai parameter garam bermerek dan air mineral bermerek di antara responden berdasarkan demografi. 
Tabel. 2 Analisis varians berdasarkan karakteristik demografi mengenai parameter mempengaruhi pembelian garam dan air mineral bermerek

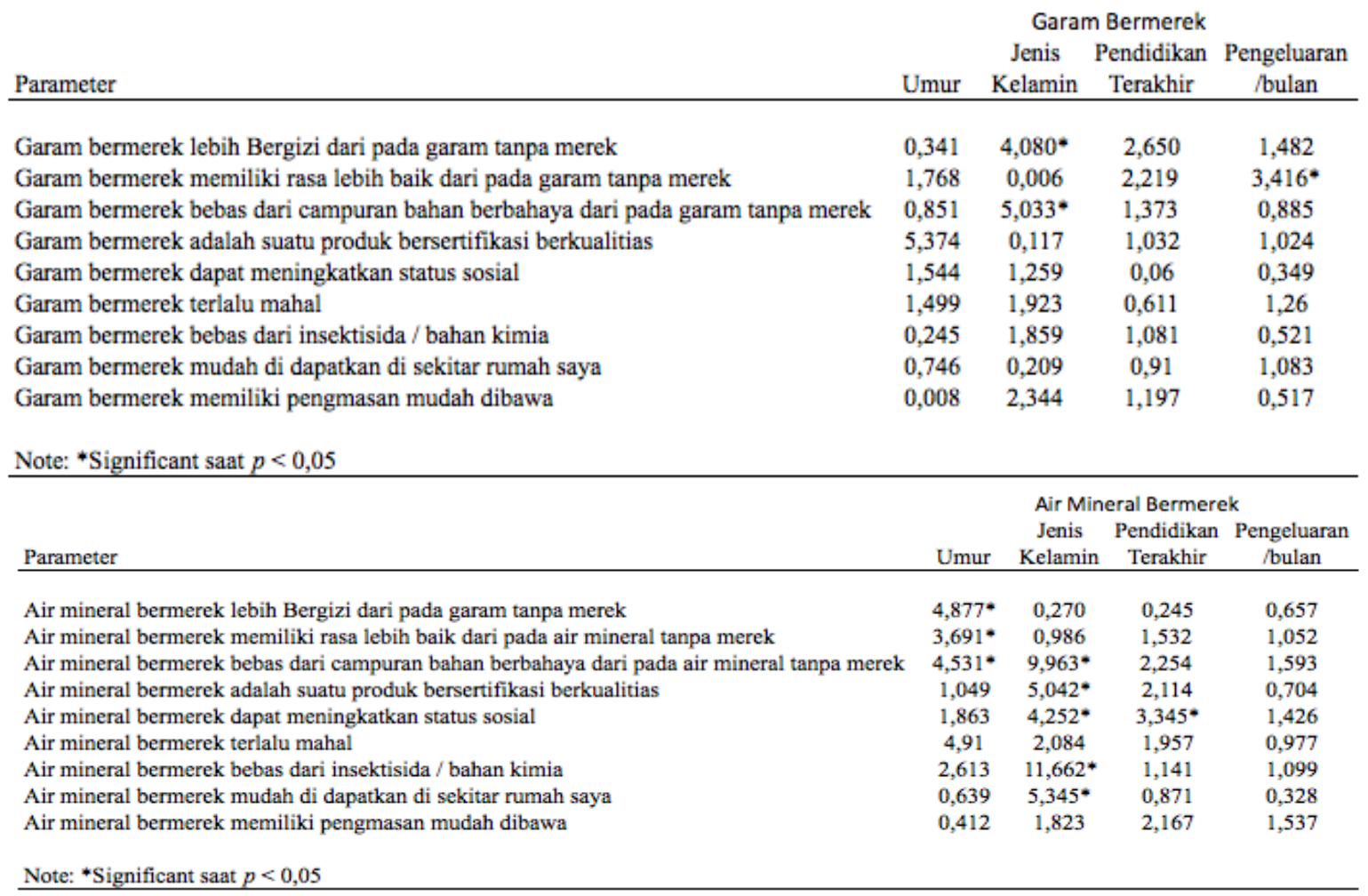

Para responden diminta untuk menilai berbagai faktor yang mempengaruhi pembelian garam bermerek dan air mineral bermerek dengan skala likert. Dalam pertanyaan ini, responden melaporkan bahwa ketersediaan informasi gizi, referensi dari teman dan saudara, dan harga adalah tiga teratas seagai faktor penting yang mempengaruhi pembelian garam bermerek.

Responden diminta untuk menilai berbagai faktor yang mempengaruhi pembelian garam bermerek dan air mineral bermerek dengan skala likert. Dalam pertanyaan ini, responden melaporkan bahwa ketersediaan informasi gizi, referensi dari teman dan saudara, dan harga adalah tiga teratas seagai faktor penting yang mempengaruhi pembelian garam bermerek. Ketersediaan informasi gizi masih sebagai peringkat teratas, diikuti oleh harga dan ketersediaan mudah yang mempengaruhi pembelian air mineral bermerek. (Tabel. 3)

Tabel. 3 ( Hasil Persepsi Responden Terhadap Beberapa Faktor Garam dan Air Mineral

\begin{tabular}{|c|c|c|c|c|c|c|c|c|c|c|c|c|}
\hline & Harga & $\begin{array}{c}\text { Merek } \\
\text { Dagang }\end{array}$ & $\begin{array}{l}\text { Ketersediaan } \\
\text { yang Mudah }\end{array}$ & $\begin{array}{l}\text { Tampilan } \\
\text { Menarik }\end{array}$ & $\begin{array}{l}\text { Rekomendasi } \\
\text { Pengecer }\end{array}$ & $\begin{array}{c}\text { Referensi dari } \\
\text { Teman dan } \\
\text { Saudara } \\
\end{array}$ & Pengemasan & $\begin{array}{l}\text { Ketersediaan } \\
\text { informasi gizi }\end{array}$ & $\begin{array}{c}\text { Informasi } \\
\text { Tanggal } \\
\text { Kadaluwars }\end{array}$ & $\begin{array}{c}\text { Informasi } \\
\text { Mengenai } \\
\text { Umpan }\end{array}$ & $\begin{array}{l}\text { Iklan yang } \\
\text { Menarik }\end{array}$ & $\begin{array}{l}\text { Nilai untuk } \\
\text { Uang }\end{array}$ \\
\hline \multicolumn{13}{|l|}{ Garam } \\
\hline Mean & 3,74 & 3,69 & 3,79 & 2,96 & 3,43 & 3,76 & 3,37 & 3,77 & 3,49 & 3,67 & 2,98 & 3,6 \\
\hline Responden & 200 & 200 & 200 & $200^{\circ}$ & 200 & 200 & 200 & 200 & 200 & 200 & 200 & 200 \\
\hline \multicolumn{13}{|l|}{ Air Mineral } \\
\hline Mean & 3,7 & 3,68 & 3,78 & 3,48 & 3,64 & 3,61 & 3,26 & 3,58 & 3,8 & 3,52 & 3,57 & 3,51 \\
\hline
\end{tabular}

\section{Bermerek )}

Hasil perbandingan tanggapan konsumen pada parameter yang berbeda mengenai sikap terhadap garam bermerek sehubungan dengan demografi ( usia, jenis kelamin, pendidikan, dan penghasilan) menunjukan bahwa ada perbedaan signifikan dalam tanggapan mengenai faktor "nilai untuk uang" yang diberikan oleh responden yang termasuk dalam kategori umur yang berbeda dan "uampan balik pelanggan" untuk air mineral bermerek. Oleh karena itu, kita dapat menyimpulkan bahwa hipotesis kedua terbukti terdapat perbedaan signifikan 
persepsi yang signifikan mengenai pentingnya berbagai faktor yang mempengaruhi pembelian garam bermerek dan air mineral bermerek di antara responden berdasarkan demografi. (Tabel. 4)

Tabel. 4 Analisis varians berdasarkan karakteristik demografi mengenai faktor-faktor yang mempengaruhi pembelian garam dan air mineral bermerek

\begin{tabular}{|c|c|c|c|c|}
\hline \multirow[b]{2}{*}{ Parameter } & \multicolumn{4}{|c|}{ Garam Bermerek } \\
\hline & Umur & $\begin{array}{c}\text { Jenis } \\
\text { Kelamin }\end{array}$ & $\begin{array}{c}\text { Pendidikan } \\
\text { Terakhir }\end{array}$ & $\begin{array}{c}\text { Pengeluaran } \\
\text { /bulan }\end{array}$ \\
\hline Harga & 0,839 & 0,082 & 0,321 & 0,315 \\
\hline Merek Dagang & 2,43 & 0,321 & 0,862 & 0,789 \\
\hline Ketersediaan yang Mudah & 0,163 & 2,531 & 0,644 & 0,646 \\
\hline Tampilan Menarik & 1,283 & 0,568 & 0,068 & 0,298 \\
\hline Rekomendasi Pengecer & 1,031 & 1,331 & 0,543 & 0,876 \\
\hline Referensi dari Teman dan Saudara & 0,641 & 0,413 & 0,012 & 0,569 \\
\hline Pengemasan & 0,014 & 0,002 & 0,012 & 0,298 \\
\hline Ketersediaan informasi gizi & 1,15 & 2,433 & 2,682 & 0,771 \\
\hline Informasi Tanggal Kadaluwarsa & 0,624 & 0,036 & 2,339 & 0,735 \\
\hline Informasi Mengenai Umpan Balik Pelanggan & 0,516 & 1,754 & 0,395 & 0,633 \\
\hline Iklan yang Menarik & 1,239 & 0,346 & 0,359 & 1,549 \\
\hline Nilai untuk Uang & $5,469^{*}$ & 0,503 & 1,395 & 0,846 \\
\hline
\end{tabular}

\section{KESIMPULAN}

Berdasarkan hasil analisis data didapatkan bahwa sebagian besar $(44,5 \%)$ responden dapat menyebutkan tiga garam bermerek, terdapat $22,5 \%$ responden yang hanya dapat menyebutkan satu merek garam. Sedangkan untuk air mineral bermerek 100\% responden dapat menyebutkan tiga air mineral bermerek. Kedua, kemasan yang terlihat, orang sekitar, dan bazaar adalah sumber paling penting terhadap kesadaran akan garam bermerek, dan kemasan yang terlihat, orang sekitar, dan iklan menjadi sumber paling penting terhadap kesadaran air mineral bermerek. Ketiga, parameter garam bermerek terlihat memiliki hasil yang sama pengemasan yang mudah dibawa, lebih mudah didapatkan, dan memiliki rasa yang lebih baik adalah pernyataan yang disetujui dari sebagian besar responden. parameter kualitas seperti aroma / rasa, nutrisi, bebas dari campuran berbahaya, bebas dari bahan kimia berbahaya ditemukan menjadi kualitas parameter air mineral terpenting. Keempat, terbukti jika terdapat perbedaan persepsi yang signifikan mengenai pentingnya berbagai parameter dan faktor yang mempengaruhi pembelian garam bermerek dan air mineral bermerek di antara responden berdasarkan demografi

\section{DAFTAR PUSTAKA}

Ahmed, Rizwan. (2014). Impact of Product Packaging on Comsumer's Buying Behaviour: European Journal of Scientific Research,120(2), 145-57 Data Konsumsi Garam di Indonesia tahun 2010-2014. (http://statistik.kkp.go.id/sidatikdev/Berita/Analisis\%20Produksi\%20Garam\%20Indonesia.pdf diakses 13 Maret 2018).

Data Konsumsi Air Mineral dalam Kemasan di Indonesia tahun 2014-2016. (http://aspadin.com/index.html diakses 2 Mei 2018).

Firat, A and Kutucuo. K. (2013). Consumption, Consumer Culture, and Consumer Society : Journal of Community Positive Practices, 13(1), 182-203.

Kementrian Perdagangan Republik Indonesia tahun 2012. (http://www.kemendag.go.id diakses 2 Maret 2018).

Kotler, P., and Amstrong, G. (2010). Marketing Management $\left(5^{\text {th }}\right.$ ed.). New Jersey: Prentice Hall Internasional Edition.

Mohan Kathuria, L., \& Gill, P. (2013). Purchase of branded commodity food products: empirical evidence from India. British Food Journal, 115(9), 1255-1280.

O'guinn, T., Allen, C., Semenik, R., \& Scheinbaum, A. C. (2014). Advertising and integrated brand promotion. Nelson Education. 
Scheidel, W. (2001). Progress and Problems in Roman Demography : Debating Roman Demography, 211, 1-81.

Schiffman, L.G., Kanuk, LL, 2007. Consumer Behaviour, ninth ed. Prentice-Hall Inc, NJ 


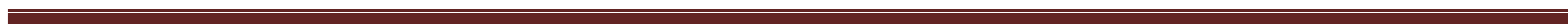
$\cdot$ 